\title{
Variables Affecting Developments of Hydroxyapatite Coating by Using Electrophoretic Deposition Technique
}

\author{
Abdulsalam Khashan Swadi*
}

Date of acceptance 16/6/2008

\begin{abstract}
Electrophoretic Deposition (EPD) process offers various advantages like the fabrication of the ceramic coatings and bodies with dense packing, good sinterability and homogenous microstructure. The variables namely (applied potential, deposition time and sintering temperature) affected the development of hydroxyapatite (HAP) coatings. The coating weight and thickness were found to increase with the increase in applied potential or coating time. Sintering temperature was found to affect in change phases of the metal, furthermore the firing shrinkage of the HAP coating on a constraining metal substrate leads to serve cracking. XRD Characterization indicates the formation of a contamination free phase pure, and the optical micrographs show the relatively uniform distribution of the HAP coatings. Analysis of the stiochiometric HAP before EPD process and after sintering indicates that the structural aspects do not change i.e. the EPD in ethanol does not affect the structure of HAP powder.
\end{abstract}

Key words: hydroxyapatite, Electrophoretic deposition, biocompatibility, sintering temperature.

\section{Introduction}

Calcium phosphate is the most ubiquitous family of bio-ceramics well known for their use in biological applications, when used to improve implant tissue osseointegration, considerable effort has been exerted to modify the implant surface stru- cture both physically and chemically $(1,2)$.

Various methods of ceramic coating developed during recent years have been considered to improve the wear and corrosion resistance of metallic implants. Some of the methods are; plasma spray, physical vapor deposition PVD, chemical vapor deposition CVD,dipping, etc. Electrochemical deposition is one method used to develop ceramic coating on metal surface, this method offers a number of advantages over other conventional coating methods (CVD, PVD, sputtering, plasma spray, etc) namely; low temperature process, low cost equipment, easy to control microstructure of coatings and can be used in any shape of substrates. These advantages make this method more attractive to metallic implants $(3,4)$.

Electro deposition is evolving as an important method in ceramic processing; there are two main processes to form ceramic films; electrophoretic deposition (EPD), in which suspensions of ceramic particles are used, and electrolytic deposition (ELD), which is based on the use of metal salts solutions. Electrolytic deposition enables the formation of thin ceramic films and nanostructures powders while EPD is an important tool in preparing thick ceramic films and body shaping $(5,6)$.

In present study electrophoretic deposition was attempted to develop hydroxyapatite coating on type 316L SS, furthermore for better adhesion between substrate and HAP coating, preferred sintering temperature have been found to producing crystalline HAP coatings. The formed coatings were analyzed for $\mathrm{Ca} / \mathrm{P}$ ratio that must be suitable for high biocompatibility.

\section{Materials and Methods}

\section{Sample Preparation}

Surface condition of the alloy plays major role in the development of HAP coating and its corrosion resistance. Type 316L SS alloy in as received mill annealed condition was cut into $11 \times 11 \times 2 \mathrm{~mm}$ size piece. All the specimens were polished up to 1000 grit $\mathrm{SiC}$ paper to bring it to uniform surface conditions. The polished specimens then washed with detergent solution, degreased with acetone and 
thoroughly washed with distilled water. Ultrasonic cleaning in acetone for 10 minutes followed this and finally the sample was rinsed in deionized water, dried and used for EPD process.

Electrophoretic Deposition Process EPD Hydroxyapatite was electrophoritically deposited on the substrate alloy surface from $2.5 \%$ suspension in ethanol. The electrophoretic yield was determined at various applied potentials for constant deposition time. Figure 1 showed the schematic representation of electrophoresis deposition system.In EPD process application of a DC field causes the charged particles to move forward and deposit on the oppositely charged electrode.HAP coated thickness was evaluated by using the technique device (Mini-Test 3000, Erichsen, W.Germany).

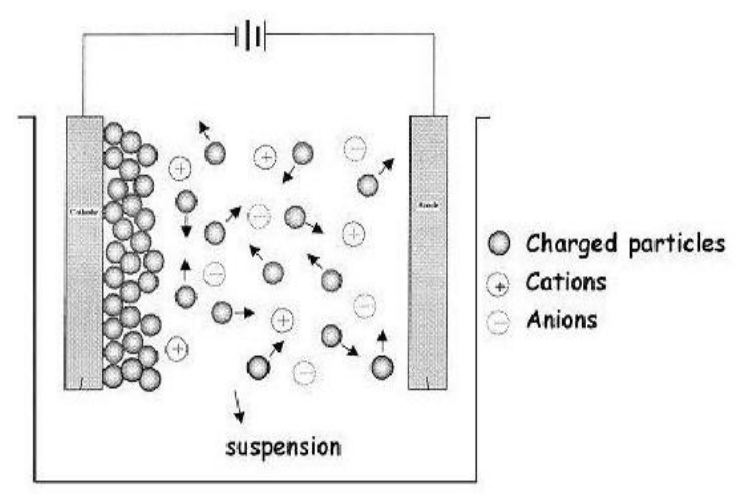

Fig. 1: Schematic representation of EPD process

\section{Results and Discussion}

Variables Affected Coating

Applied potential Vs. time

During deposition, the electric field drives the particles towards the work electrode and exerts pressure on the deposited layer. From this point, application of higher electric field (voltage) should result in higher deposition rate. The use of high voltages has the advantage of lesser deposition times and higher deposition thickness $(4,6)$.

The effective potential range for obtaining uniform HAP coatings was found to vary from 30-70 V,during the deposition process in this voltage range and coating time from 1-5 minutes, no significant hydrogen evaluation was observed and the coatings obtained were uniformly adhered. This is due to the fact that a certain value of electric field is necessary in order to overcome inter particle interactions and to allow particles to bond to the substrate. This was found to be optimum at 60 volts and 3 minutes.

\section{Coating thickness}

The changes in the coating thickness and coating weight (a) at varying potential from 20110 volt at constant time of three minutes and (b) at constant potential of 60 volt with increasing time from 1-10 minute are given in figure 2 .

The coating thickness was increased when applied potential or time increased.Karils and Berndt 1998 and Kannan et al 2002 showed that a thicker coating will give a brittle material prone to cracking under bending or shearing force. The increased in coating weight of HAP thus lead to loss of thicker coating from the metal surface due to decohesion between the surface and the coating. This was also confirmed by $(7,8)$.

\section{Effect of sintering temperature}

Sintering temperatures have a deleterious effect on the properties of the coating and the metal substrate. Low sintering temperatures can lead to weakly bond low-density coatings. High sintering temperatures result in phase changes of the metal substrate catalyzing the decomposition of HAP to anhydrous calcium phosphates $(9,10)$. Thus the system of sintering temperature was varied in the present study between $600-900 \mathrm{C}^{\circ}$ for an hour. An ideal HAP coated implant should be resistant to dissolution and posses high bond strength. The bond strength of the coatings is achieved by sintering.

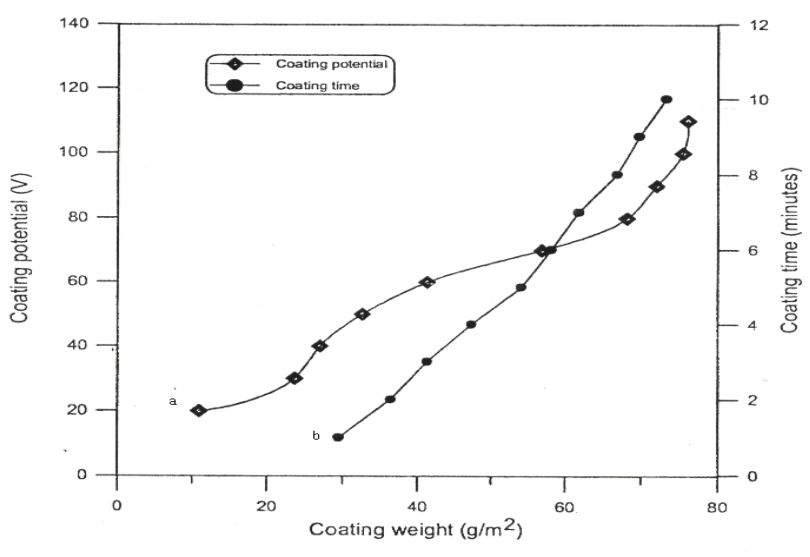

Fig. 2: Effect on variation of coating weight as a function of

(a) Coating potential at constant time of 3 minutes (b) Coating time at constant potential of 60 Volts.

\section{Coating Characterization :XRDPatterns}

The XRD patterns of HAP coated $316 \mathrm{~L}$ SS after sintering in air at $600 \mathrm{C}^{\circ} ; 800 \mathrm{C}^{\circ}$ and $900 \mathrm{C}^{\circ}$ are indexed in figure 3 . All the major 
HAP peaks were detected and indexed along with the iron peaks. Other calcium phosphate phases on the coatings were absent. For the samples sintered at $900 \mathrm{C}^{\circ}$, the 043 plane for $\alpha$ TCP (tri-calcium phosphate) was detected along with $\mathrm{Fe}$ peak. This could be due to the formation of metal-ceramic composite layer consisting of iron oxide and HAP that resulted in the formation of impurities in the coated sintered at $900 \mathrm{C}^{\circ}(1,11$, and 12$)$.

\section{EDXRF analysis}

The EDXRF spectrum of the HAP coated surface is given in figure 4 , which indicates the elemental composition of the coated substrate. Intense bonds for calcium and phosphorous were obtained. Small peaks corresponding to $\mathrm{Fe}$ and $\mathrm{FeK} \beta$ ), $\mathrm{Cr}$ and $\mathrm{Ni}$ are present in the alloy.

\section{Morphological studies}

The surface morphology of the coated sample was investigated in comparison with HAP powder using microscopic technique and the micrographs are presented in figure 5 , which showed a fairly uniform distribution of particles, which indicating that the coatings are dense and micro-porous. No cracking of the coating was observed suggesting that there was no shrinkage of the coating.

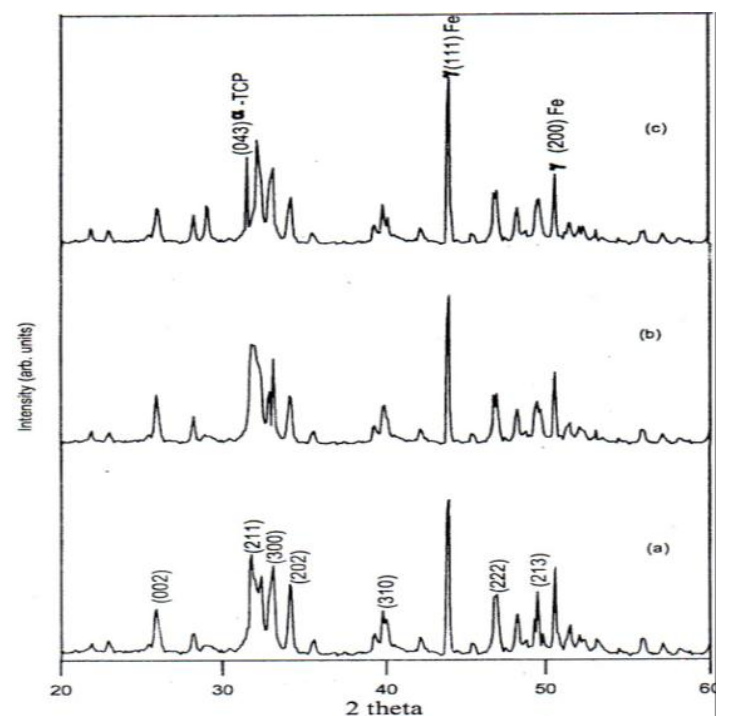

Fig. 3: XRD patterns of HAP coated 316L SS after sintering in air at (a) $600 \mathrm{C}^{\circ}$ (b) $800 \mathrm{C}^{\circ}$ and (c) $900 \mathrm{C}^{\circ}$.

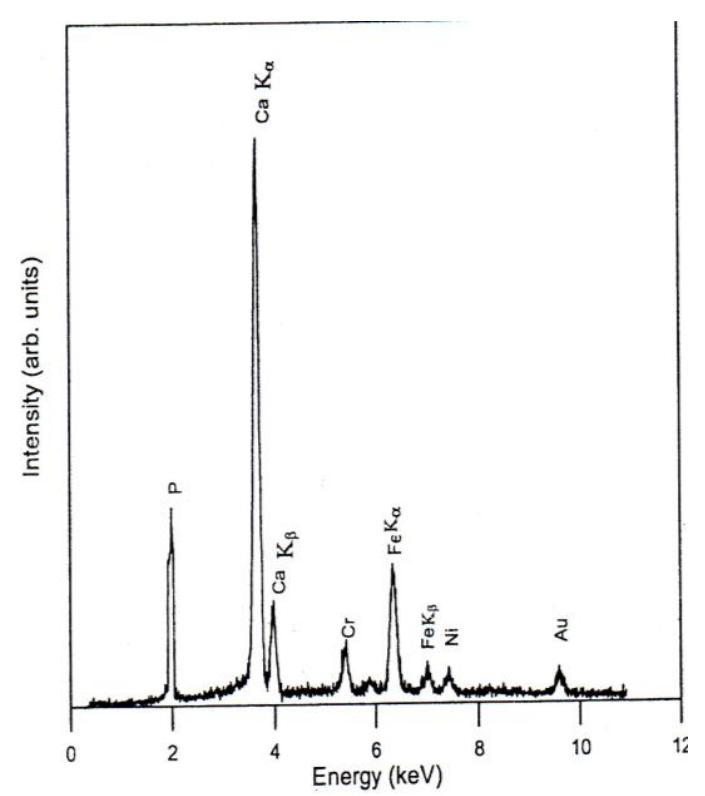

Fig. 4: EDXRF spectra at the optimum coating parameters of $60 \mathrm{~V}$ and 3 minutes after sintering at $900 \mathrm{C}^{\circ}$.

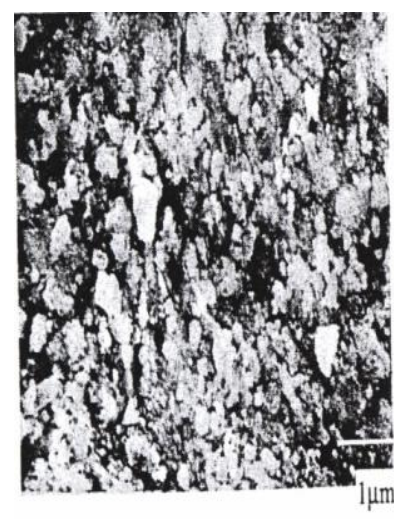

(a)

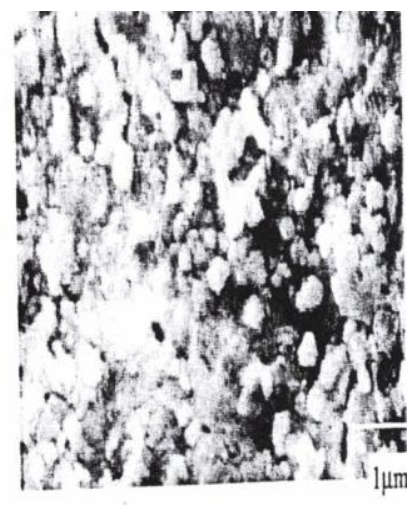

(B)
Fig. 5: Optical micrograph of (a) HAP coated type 316LSS at the optimal coating parameters and (b) HAP powder.

\section{Conclusions}

- From this study, it may concluded an using EPD process can develop a uniform and thick layer of HAP coating with aim of enhancement of the biocompatibility and structural behavior of medical implants.

- Electrophoretic deposition was chosen since it is in principle, an excellent method for uniformly coating parts with complex shape. The most important factor affecting the ratecontrolling step is hydrogen bubble formation and adsorption of water by the powder. It was observed that adsorbed water interferes with EPD and hence only sintered stiochiometric powders were used as starting materials.

- The choice of a solvent is also very important for EPD process. Organic solvents are more preferable to water since EPD in water is accompanied by significant gas evolution. 
Thus ethanol was used as solvent.The objective of using ethanol is to inhibit the formation of hydrogen bubbles and to improve the efficiency of adsorption. More ever a large coverage of HAP surface is obtained with ethanol as it gets adsorbed on calcium sites on the 100 planes.

\section{References}

1-Mitsuo N.(2002)"Recent Metallic Materials for Biomedical Applications"J. Metall. and Mater. Trans.33(A) 477.

2- Prashant N.K., Charles S., Dong H.L., Ana O.D. \& Daiwan C., (2005) "Nanostructure ued-Calcium Phosphates for Biomedical Applications" Acta. Biomaterialia, 165.

3- Kannan S., Balamurugan A. and Rajeswari S.(2002) "Development of calcium phosphate coatings on type $316 \mathrm{~L}$ ss and their in vitro response" J. Trends. Biomat. Artif. Organs. 16(1) 8-11.

4- Milev A., Green D., Chai C.S. and BenNissan B. (2005), "Coating of the Orthopedic Titanium Alloys with Sol-Gel Derived Hydroxyapatite" A. Dep. Chem. of Mat. Science, Univ. Of Tech., Sydney

5- Karlis G.A.\& Christopher B.C.(2002), "Biomedical Application of Apatites" J. Mineralogical Society of America, 4817.

6-Zhitomirsky L.,Balamurugan A.and Rajeswari S.(2000),"Development of Calcium Phosphate Coatings Type 316Lss and Their in Vitro Response" J. Trends. Biomat. Artif. Organs. 16 (1) 1.
7-Ricardo S.M.,Maria L.M.\&Rui R.L. (2003),"Degradation Characteristics of Hydroxyapatite Coating on Orthopedic TiAlV in Simulated Physiological Media Investigated by Electrochemical Impedance Spectroscopy" J. Bio. Mat. 244213.

8-Robert B.H.and Richard W.(2006), Formation and transformation of amorphous calcium phosphates on $\mathrm{Ti}$ alloy surfaces during atmospheric plasma spraying and their subsequent in vitro performance, J. Bio. Mat. 27823.

9- Sridhar T.M,Rajeswari S.,Subbaiyan M. and Kamachi U.M. (2000), "Sintering Effects on Hydroxyapatite Coated and It's Impedance Behavior "FAME, Bangalore, 265.

10- Nithyanantham T., kandassamy C., Gnanam F.D.(2002), “The Effect of Powder Processing on Densification, Microstructure and Mechanical Properties of Hydroxyapatite",J. Ceram. International. vol.28, 355.

11- deCampos J.B., Oliveria M.V.,Pereira L.C. and eRossi A.M.(2003),"SEM Microstructure Observations and XRD Measurements in Ti/HAP Powder Sintered Composites". Acta. Microscopia. 12 (C) 23.

12- Takayoshi N.,Atsuyuki T.and Yukichi U. (2002), "Variation in Crystallinity of Calcium Phosphates by Mechanical Grinding and Subsequent Heat Transfer"J.Metall. and Mater. Trans. A.33 521.

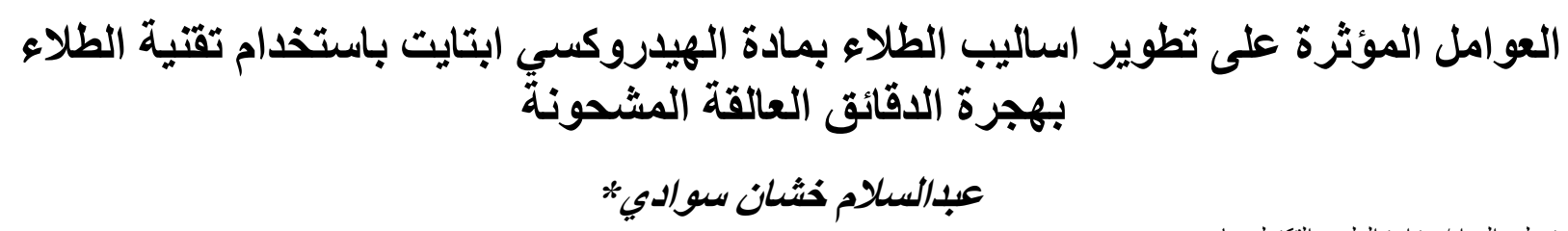

*دائرة علوم المو اد/ وزارة العلوم و التكنولوجيا

تتميز تقنية الطلاء بهجرة الدقائق العالقة المشحونة بفو ائد متعددة خصوصـا في عمليات طلاء المو اد السير اميكية و السبائك المعدنية

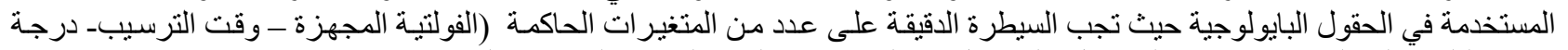

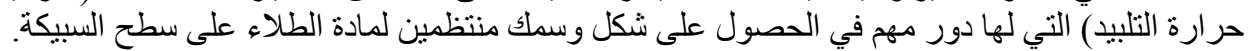

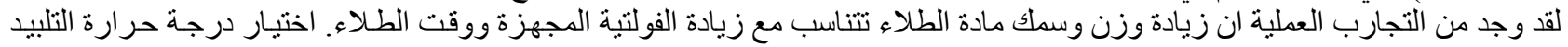

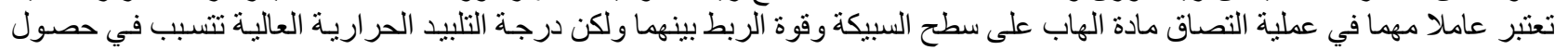

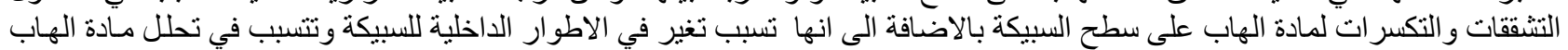
وتغير خو اصها.

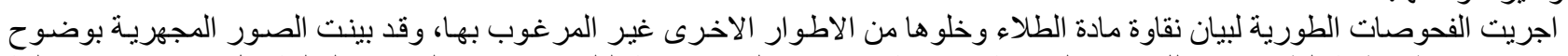

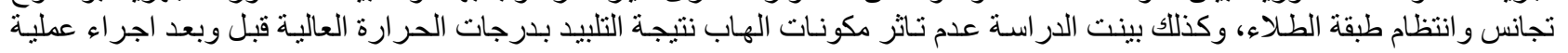
الطلاء. 